\title{
Borwort.
}

Die Sdrrift, welde id biermit bem tbeologinden $\mathfrak{P}_{u b l i .}$ fum übergebe, tritt mit febr beidcibenen 2 njprüden in bie Belt. Sie if red)t eigentlid ein R̄inb bes̉ Bebürfniffes. Seit einer Reibe von 3abren babe id an biefiger 5odfdule in oem fo furjen Sommer/emefter Borlejungen über 5omiletif gebalten. Das Beffreben, in Den brei wödentliden Stunben, melde bie Borlejung in 2̂njprud) negmen fann, bie 3eit nidt mit, wenn aud auf ein Minimum rebucirten, bod immer niфt gang zu vermeibenden 2lufzeidnungen ber 3ubörer zu vertieren, fonbern möglidif viel, namentlia für bie praftifien llebungen, zu geminnen, musite mid balb allf ben Bebanten bringen, ein Eompentium auş̧uarbeiten, um burd) beffen 3ugrunbelegung für weitere theoretifde Grörtermingen, wie für bie praftifden Uebungen mir freies zelb ju seridaffen. Die unerwartet freunblide 2lufnabme, beren meine vor fünf Jabren eridienenen "Srunbjŭge Der (Frziegungolebre" (iid) ju erfreuen batten, beftimmte mid, ber yorliegenden Sdrrift Diefelbe Einridtung ju geten, bie Bertbeilung bes Stoffes unter Yjaragrapben nämlid beigubebalten, biejen legs: teren aker nidt bie form furzer Regriäte ju geben, fondern 
Die eingelnen Sauptpunte in ignen weitläufiger ou entroideln, unb Dann in Den Anmerfungen baz im Yyaragrafben AHzge= fprod,ene, namentlid Durd Anfübrung vermandei uno burd Rritif abweid)enber Anfidten, näber zน begrünben unb ę cuf bie einzelnen fälle ber brariz unmittelbar anjumentent. Diçe Form Des Budes, boffen wir, wirb bem 3weat eines Som = pendiums niđt entgegen (eyn, unb es bod) aud auferbalb bes afabemifden Sebriaales braudbar uno insbefonbere aud für Den Praftifer lesbar maden, auf beflen Urtbeil wir bei biefem auf eine praftifate Dièciplin fĭ bejiebenten Berfude befon= Der begierig wären. Inoem wir unt eimerieits jum Grunb= fag madten, ber wiffenidaftliden Sdjärfe nidts ju vergeben, anbrerfeits, fo weit es obue jablreidere uno weitläufigere Iufjäblung von Beifpielen, wofür Der Raum nidt ausreidte, gefdeben fonnte, bie Bejiebung ber Theorie auf Die Jraris nadjuweifen nie unterlieken, glauben wir, tá unfere Sdrift jwifaen ber von.Stweizer und ber von Yalmer eine gewiffe mittlere Etellung sinnegmen werbe, neben welden beiben Büळerl zu exiftiren, jie auperbem faon burd ibren viel geringeren llmfang ein Redt baben bürfte. उ由 bemerfe

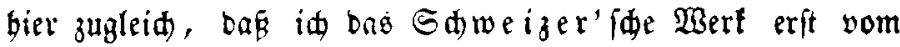
14. \$. an vergleiden tounte, jebod) aum für bie wefentlidften Grunbfäkse ber früberen \$\$. in ibm eine febr erfreulide $\mathfrak{B e}=$ fảtigung fanb.

Die Borlefungen, aus welden biefe Shrift bervorges gangen iff, batten ben 3wed, angebenben Tbeologen bie erfte

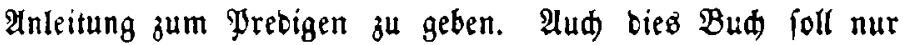
Säke alfitellen, von welden wir erwarten, baßz ber Geiftide bei ibrer $\mathfrak{B e f o l g u n g}$ feiner $\mathfrak{A} u f g a b e$ ald Prediger genügen werbe, ullo in biefem Sinne war unfer eifrigftes Beffeben, fo wenig

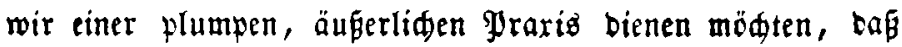
bas Bud ber Rubm, ein redt fraftifdes ju feyn, fid) er=

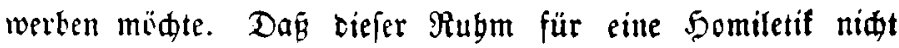
eten leidt) j" gewimnen ift, fdeint bie Erfabrung zll beweifen, 
melde zeigt, Daßs bie praftifden (Geiftliden fait um teinte theo= logifde Disciplin to wenig fid befümmern, ald gerabe um Die Tbeorie oer Somiletif, obgleid biefe auf bie wefentlidfte

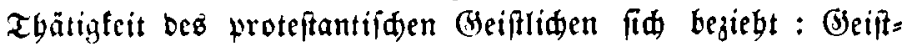
lide, rie Durd) Somilctifen tüdtige Jrebiger gemorben find,

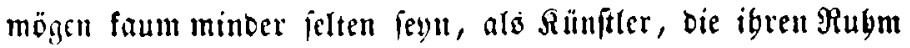

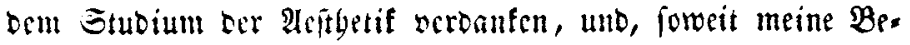
fammidaft mit traftijden (briftliden reidst, babe id nidst wabrgenommen, baß̈ unter ibuell cille Somiletif bauernbes Intereffe unb nadbaltigen Einbruă berborgebradt bätte, aū̄cr ber Ialmer'fhen. Sffenbar bat bics feinen Grunt Darm,

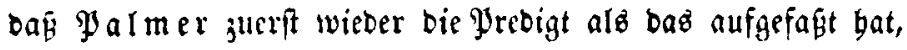
was fie wirtlid feyn foll, ill ibrer concreten Beftimmtbeit

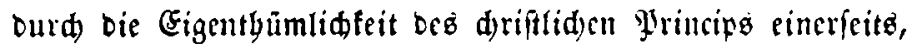
unb bie Inbinibualität be yrebigers antererfeits; wäbrent Dis gangbaren Rebrbüder ber 5omiletif in ibren von ber (3)rammatif, Stnlifif, Nbetorif nur ertorgten abftracten $\Re e=$ geln tbeils fo allgemein fits bielten, baßz Die Beziebung Der Boridrift auf die Yraris gar nid)t zu finben war, tyeils fo ipeciell, Daß̧ lie Dem Orebiger, Der nađ ibnen fí bätte ridten wollen,

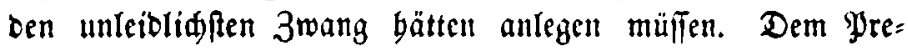
biger für jeben Betanten, jebeo $\mathfrak{B}$ ort, jede Dliene uno (Ge= herbe ein beftimmtes (Geles rorjuid)reiben, wonad) er umnittel: bar hid ridten fömute, Darauf muß Dic Somiletif verjidjten ullo wenn fie bas tennod leiften will, fo leiftet fie nid)ts; bas aber fann fie, baß fie die allgemeinen Grunbjäbe ber fird)= liden Berebfamfeit auffellt, vor bem burduus Anftöfigen,

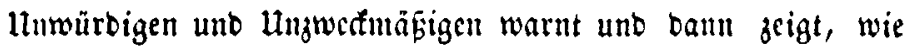
auf bem alfo begrünbeten unb begrengten Gebiete ber Yrebiger, nad) Mnągabe feiner, von einer innigen uno zu lebenbiger Mittbeilung begeifternben driftliden lleberjeugung burdbrungenen Inbivibualität, fiф frei bervegen müife. Sn einer folden 5o: miletif, und wir wïnfden, bá bie unire alb eine foldi fid

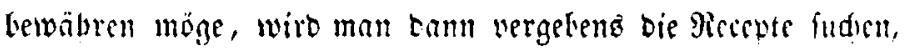


nad beren 2(nleitung jeber Beliebige aus ver/diebenen 3utbaten eine regeltredte Yrebigt julammeniegen tönnte; wobl aber wirb fie im Stanbe fegn, ben Yrebiger auf ben redten Stanbpuntt zu fellen, berrfdente Berftöß̄e zu befeitigen uno zur Aneignung beffen anjuregen, was ben tü山tigen Srebiger madt : einer roblbegrünbeten, innigen driftiden Ueberzeugung unb ber F̧äbigleit biefer ibren wabren, warmen, $\mathfrak{t}$ aren, indivibuellen

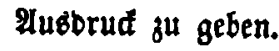

MRögliđ, bak Die Sdrift bie Zeident ber Zeit an fidh trägt, in welder ibre leß̧tc Ueberarbeitung, bie mit verfloffe= nem Februar begonnen wurbe, entitanben iff. Fơ war nidt reidt, unter ben Einflüffen ber politifden 2lufregung, woburd

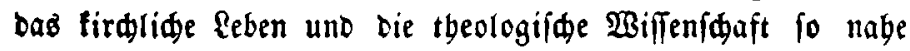
berübrt wirb, immer bie ju einer berartigen Arbeit nötbige

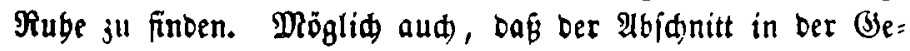
fdidte ber Somiletif, welder bas erfe Errwaden einer volfs = tgümliden Wrebigtweife im beutiden Mittelalter barftellt, eine gebohenese Etimmung verrätb. (Es wärbe fid) Dann ver (Fin: orna barin abgeipiegelt baben, welden auf ben Berfaffer bif Radridt berworbrad)te, Dā an bie Spige eer Megicrung feines engeren Baterlandes der Mann erboben worden ien,

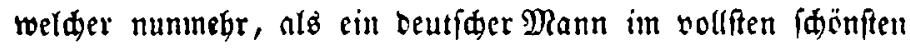
Sinne Des Bortes, in Der Berfammlung ter Bertreter bes beutiden Bolfes ben Borlï jübrt. Alber hat fid senn bie Sirde biefer politifden 2lufregung zu freuen? Şört man nid)t

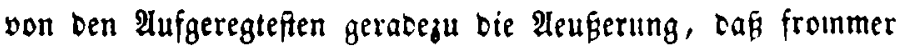
Sinn und politifide Bildung fid Direct entgegengefeght feyen? Dak es mit Der Freibeit $j$. B. in Deutidland nur oérwegen niđt redt fortwolde, wail ber 2 tbeismus unter ung nod nidts

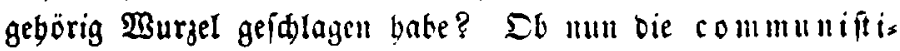

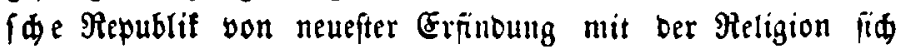
niđt vertragen tỏnne, baş wiा̄en wir nidt, trauen ibr aber bas, menn aud fonft nidt ricl, 3u; bak aber bie auf patriotif uno nittionalem Boren crmadiene wabre folitilde sreibeit 
vielınegr, twie bie Ratiouen felthit, fitet mit Der wabren Neligiofität ftieg und fiel, das wilīen wir ganz gewín, Denn bie (Bes fdiфte zeigt es auf jebem Blatte, uno eben io gewis willen wir, baßs fo lange beutide Borföthünlidfcit nid)t völlig ver= nidtet ift, aud für Refigion und (Egriffentburt nod eine Stätte bleiben wirb. Gebt nun, und das wolle Bott geten! aus ben Etürment und Rämffen ber (Segennuart unfer grókes Boll einig, ftarf und froi berwor, baun zweifeln wir nidt,

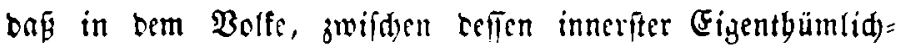

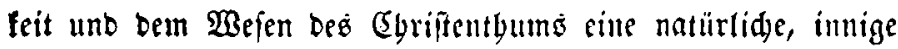
Berwanbtfdaft beftegt, aus Defien Gemütbstiefe uno fittlidem Ernfte einft bie Biebergeburt Der Rirde bervorging, aud in Zufunft bie drifflide אirde zu einem freien, frifden, innigen unb reiden Reben neu erblüben werbe! $\mathfrak{B i e}$ aber aud ber

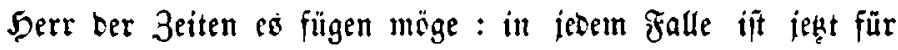
unfer Birfen infofern eine gute 3eit gefommen, alo bie $\mathfrak{s}$ irde (id) nun nid)t meḅr braud)t nadjagen ju lailen, baß jie, als cine bolizeianiant tes Etaates non beionterer Form, nur von riefem erbalten werte, als fie rielmebr nun burd eigne Seraft fid) erbalten muś, und ibre Diener angemiejen fint, burd innere Aneiguming und lebendige Berfündigung bes inneren

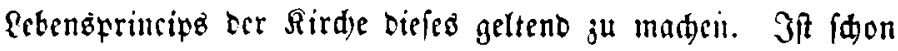
baburd sorjugstweífe für bas auf Ueberzeugung mirfenbe le=

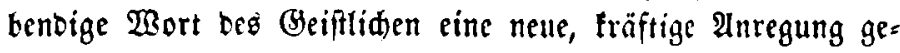
geben, fo foumt biefer won einer andern Seite ter ermadte Siun

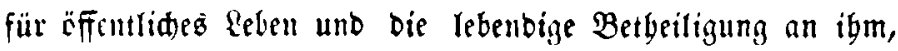

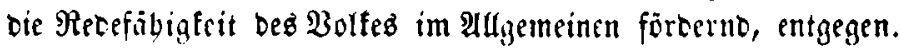
Ilno io fdicen mir sieie 2 nnweifung zur geiftliden Beredjamteit in Das fürmende und zum Ibeil feindid ftürmende Reben bin= aus im Bertrauen auf ben, ter da fpridt: : 5 immet und Erbe werbentergeben aber meine Borte werben nid)t vergeben!" Fat ung Dad) bereits Die Beriammlung Ler Bertreter Des deutiflen Bolfes in franffurt ben Bencio

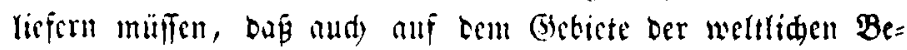


reb/amfeit fortmäbreno bie $\mathfrak{B a b r b e i t}$ gill, welde wir, als unferen Stanbpunft darafterifiteno, nad ben Borten eines

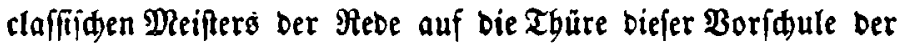

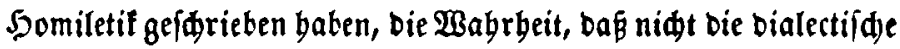
Gewanbtbeit, und bie oratorif由e Runit vorgugimeife, fonbern

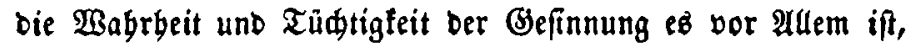
was ber Rabe ibren Einbrud fidert unb fomit ben grofen Rebner eigentlit madt.

Gießen ben 6. Juli 1848.

\section{Gruftav Baur.}

